\title{
Cerebrovascular autoregulation and arterial carbon dioxide in patients with acute respiratory distress syndrome: a prospective observational cohort study
}

\author{
Ursula Kahl ${ }^{1 \dagger}$, Yuanyuan $\mathrm{Yu}^{1 \dagger}$, Axel Nierhaus ${ }^{2}$, Daniel Frings ${ }^{2}$, Barbara Sensen ${ }^{2}$, Anne Daubmann $^{3}$, \\ Stefan Kluge ${ }^{2}$ and Marlene Fischer ${ }^{1,2^{*}}$ (i)
}

\begin{abstract}
Background: Early hypercapnia is common in patients with acute respiratory distress syndrome (ARDS) and is associated with increased mortality. Fluctuations of carbon dioxide have been associated with adverse neurological outcome in patients with severe respiratory failure requiring extracorporeal organ support. The aim of this study was to investigate whether early hypercapnia is associated with impaired cerebrovascular autoregulation during the acute phase of ARDS.

Methods: Between December 2018 and November 2019, patients who fulfilled the Berlin criteria for ARDS, were enrolled. Patients with a history of central nervous system disorders, cerebrovascular disease, chronic hypercapnia, or a life expectancy of less than $24 \mathrm{~h}$ were excluded from study participation. During the acute phase of ARDS, cerebrovascular autoregulation was measured over two time periods for at least $60 \mathrm{~min}$. Based on the values of mean arterial blood pressure and near-infrared spectroscopy, a cerebral autoregulation index (COx) was calculated. The time with impaired cerebral autoregulation was calculated for each measurement and was compared between patients with and without early hypercapnia [defined as an arterial partial pressure of carbon dioxide $\left(\mathrm{PaCO}_{2}\right) \geq 50 \mathrm{mmHg}$ with a corresponding arterial $\mathrm{pH}<7.35$ within the first $24 \mathrm{~h}$ of ARDS diagnosis].
\end{abstract}

Results: Of 66 patients included, 117 monitoring episodes were available. The mean age of the study population was $58.5 \pm 16$ years. 10 patients (15.2\%) had mild, 28 (42.4\%) moderate, and 28 (42.4\%) severe ARDS. Nineteen patients (28.8\%) required extracorporeal membrane oxygenation. Early hypercapnia was present in 39 patients (59.1\%). Multivariable analysis did not show a significant association between early hypercapnia and impaired cerebrovascular autoregulation ( $B=0.023$ [95\% Cl $-0.054 ; 0.100], p=0.556)$. Hypocapnia during the monitoring period was significantly associated with impaired cerebrovascular autoregulation $[B=0.155$ ( $95 \% \mathrm{Cl} 0.014 ; 0.296), p=0.032]$.

Conclusion: Our results suggest that moderate permissive hypercapnia during the acute phase of ARDS has no adverse effect on cerebrovascular autoregulation and may be tolerated to a certain extent to achieve low tidal volumes. In contrast, episodes of hypocapnia may compromise cerebral blood flow regulation.

Trial registration ClinicalTrials.gov; registration number: NCT03949738; date of registration: May 14, 2019

\footnotetext{
${ }^{*}$ Correspondence: mar.fischer@uke.de

†Ursula Kahl and Yuanyuan Yu authors contributed equally to the study

${ }^{1}$ Department of Anesthesiology, University Medical Center Hamburg-

Eppendorf, Martinistrasse 52, 20246 Hamburg, Germany

Full list of author information is available at the end of the article
} in this article are included in the article's Creative Commons licence, unless indicated otherwise in a credit line to the material. If material is not included in the article's Creative Commons licence and your intended use is not permitted by statutory regulation or exceeds the permitted use, you will need to obtain permission directly from the copyright holder. To view a copy of this licence, visit http://creativeco mmons.org/licenses/by/4.0/. 
Keywords: Cerebral blood flow, Hypercapnia, Hypocapnia, Respiratory failure, Extracorporeal membrane

oxygenation

\section{Background}

The acute respiratory distress syndrome (ARDS) is a respiratory failure of acute onset, characterized by bilateral pulmonary opacities and severe hypoxemia that cannot be fully explained by cardiac failure or fluid overload [1]. ARDS is common in the intensive care unit (ICU) accounting for about $10 \%$ of ICU admissions [2]. Despite advances in the management of ARDS, the mortality remains high with up to $46 \%$ in severe ARDS [2]. ARDS survivors suffer from long-term physical disability and cognitive impairment [3].

To allow for low tidal volumes and to avoid ventilatorinduced lung injury, the concept of permissive hypercapnia has been proposed in the 1990s [4]. Lower tidal volumes with a moderate hypercapnic acidosis have been shown to improve outcome after ARDS [5]. However, controversy remains on the effects of hypercapnia in ARDS owing to the results of numerous experimental studies suggesting impaired immunological, alveolar epithelial, and hemodynamic function [6-8]. A secondary analysis of three prospective observational trials showed increased ICU mortality in patients with ARDS and early hypercapnia [9]. Aside from hypercapnia, fluctuations of carbon dioxide $\left(\mathrm{CO}_{2}\right)$, have been associated with life-threatening neurological complications in patients requiring extracorporeal membrane oxygenation (ECMO) [10]. Importantly, $\mathrm{CO}_{2}$ is one of the most potent vasoactive substances acting on the cerebral circulation, with hypercapnia leading to vasodilation and hypocapnia inducing vasoconstriction [11].

Cerebral blood flow is tightly regulated by autoregulation of the cerebral circulation to ensure a continuous supply of oxygen and nutrients meeting the high cerebral metabolic demand [12]. Cerebrovascular autoregulation (CVA) mediates vasodilation in response to hypotension to avoid cerebral hypoperfusion with the risk of ischemia [13]. In contrast, CVA induces vasoconstriction in response to hypertension to prevent cerebral hyperperfusion [13]. Importantly, there is considerable inter- and intraindividual variation in the upper and lower thresholds of CVA, depending, amongst others, on chronic changes of the cerebral vasculature, the influence of anesthetics, fluctuations in $\mathrm{PaCO}_{2}$, and various other mechanisms [13]. Impaired CVA has been observed in critically ill patients and is associated with adverse neurocognitive outcome [14-16].
The aim of this study was to investigate whether early hypercapnia is associated with impaired CVA during the acute phase of ARDS.

\section{Materials and methods \\ Study registration and ethical information}

Ethical approval for this study (serial number PV5872) was obtained from the ethics committee of the Hamburg Chamber of Physicians on November 8th, 2018. Oral and written informed consent were obtained from the patient or legal guardian. Details on the informed consent procedure are provided in Additional file 1.

\section{Design, setting, and participants}

This prospective substudy is part of an observational cohort study that follows two aims: (1) to investigate whether early hypercapnia is associated with impaired CVA during the acute phase of ARDS; (2) to assess the association between impaired CVA and self-reported cognitive failures and health-related quality of life. We enrolled patients between December 2018 and November 2019. Adult patients, who were treated for ARDS according to the Berlin definition at the Department of Intensive Care Medicine of the University Medical Center Hamburg-Eppendorf, were screened for eligibility [1]. Patients with a history of central nervous system disorders, cerebrovascular disease, chronic hypercapnia, or a life expectancy of less than $24 \mathrm{~h}$ were excluded.

\section{ARDS management}

Patients with moderate or severe hypoxemic respiratory failure refractory to high-flow oxygen or non-invasive ventilation were intubated and mechanically ventilated according to current guidelines and institutional standard operating procedures $[17,18]$. Permissive hypercapnia was accepted as long as the arterial $\mathrm{pH}$ was higher than 7.2 to ensure lung-protective ventilation with tidal volumes of max. $6 \mathrm{ml} / \mathrm{kg}$ of ideal body weight (IBW).

Adjunctive therapies included proning, administration of inhalational nitric oxide, and veno-venous ECMO (vvECMO) and were applied according to international and national guidelines $[17,19,20]$. Details on ARDS management throughout the study period are described in Additional file 1. 


\section{Definition of hypercapnia}

Early hypercapnia at ARDS onset was defined as arterial partial pressure of $\mathrm{CO}_{2}\left(\mathrm{PaCO}_{2}\right) \geq 50 \mathrm{mmHg}$ with a corresponding $\mathrm{pH}<7.35$ within the first $24 \mathrm{~h}$ of ARDS diagnosis. The cut-off for hypercapnia was chosen according to Nin et al., who had shown that a $\mathrm{PaCO}_{2} \geq 50 \mathrm{mmHg}$ within the first $48 \mathrm{~h}$ of mechanical ventilation was significantly associated with higher mortality [9].

$\mathrm{PaCO}_{2}$ during measurement refers to the mean value of two blood gas analyses performed at the beginning and at the end of each CVA monitoring period. $\mathrm{PaCO}_{2}$ values were categorized as "normocapnia" (35$50 \mathrm{mmHg}$ ), "hypocapnia" (<35 mmHg), and "hypercapnia" (>50 mmHg).

\section{Monitoring of cerebrovascular autoregulation}

During the acute phase of ARDS, i.e. within the first 6 days of diagnosis, CVA was measured twice with a minimum interval of $24 \mathrm{~h}$ between measurements [21]. Each measurement period had a duration of 60-90 min. CVA was measured during stable respiratory status: one member of the study team supervised the measurement and ensured that ventilation settings $\left(\mathrm{FiO}_{2}\right.$, respiratory rate, inspiratory pressure, positive end-expiratory pressure) were not changed from $30 \mathrm{~min}$ before CVA monitoring until measurement completion. If ventilation settings had to be changed for clinical reasons, the measurement was interrupted and resumed later. In patients with vv-ECMO, the CVA measurement was not started until at least $5 \mathrm{~h}$ after the beginning of vvECMO therapy. For the monitoring of CVA, we used the time correlation method which has been described in detail previously [22-24]. In brief, the cerebral oxygenation index $(\mathrm{COx})$ is calculated from mean arterial pressure (MAP) and cerebral oxygenation $\left(\mathrm{rSO}_{2}\right)$. The MAP was measured continuously with an intra-arterial catheter (Leader-Cath, VYGON GmbH \& Co KG, Aachen, Germany) placed in the radial or femoral arteries. Cerebral oxygenation was measured non-invasively with near-infrared spectroscopy (INVOS ${ }^{\mathrm{TM}} 5100$ Cerebral Oximeter, Medtronic, Minneapolis, Minnesota). From the MAP and $\mathrm{rSO}_{2}$ values, the COx was depicted as a moving linear correlation coefficient based on a sliding 300-s window that was updated every $10 \mathrm{~s}(\mathrm{ICM}+$, Cambridge Enterprise, Cambridge, UK). A COx close to zero indicates intact CVA. In contrast, a positive correlation between $\mathrm{rSO}_{2}$ and MAP indicates impaired CVA. COx levels $>0.3$ are considered as an indicator of a pathological cerebrovascular autoregulatory response to systemic blood pressure fluctuations [25]. The time with impaired CVA was defined as the percentage of the total monitoring time with a cerebral oxygenation index $\mathrm{COx} \geq 0.3$.

\section{Power calculation}

We hypothesized that CVA would be more impaired in patients with early hypercapnia compared with patients without early hypercapnia. We aimed to analyze a consecutive sample of patients with ARDS over a 12-month period. Assuming a type I error of 5\% (two-tailed hypothesis) and a power of $80 \%$, a sample size of 50 patients would be sufficient to achieve an effect size of 0.81 . With a standard deviation of 0.21 , a mean difference of 0.17 in COx between groups would be statistically significant. This difference is considered as clinically relevant. We used PASS Version 15.0.3, module "Two-Sample t-Tests using Effect Size" (NCSS, LLC. Kaysville, Utah, USA).

\section{Data collection}

Information on medical history and regular medication was obtained from the patient, next of kin, or the referring physician. Data on critical care management including disease progression, current medication, laboratory parameters, and mechanical ventilation was retrieved from the electronic patient data management system (ICM, Drägerwerk AG \& Co. KGaA, Lübeck, Germany) on each day of measurement. The Sequential Organ Failure Assessment score was used to assess sepsis-related multi-organ affection at the time of measurement.

\section{Statistical analysis}

For descriptive statistics, mean and standard deviation or total numbers with percentages were used. Baseline demographic and clinical characteristics were compared between patients with and without early hypercapnia with the Chi-square test, Fisher's exact test, or MannWhitney- $U$ test as appropriate. Patients who died before informed consent was obtained were not considered in the statistical analysis. Patients who died before the second monitoring episode were included in the analysis.

For statistical evaluation of association between early hypercapnia and impaired CVA, a linear mixed model fit by restricted maximum likelihood was built including the dependent variable (relative time with impaired CVA), the independent variable of primary interest (early hypercapnia vs. no early hypercapnia) and clinically relevant variables with potential confounding influence (age, Sequential Organ Failure Assessment score, ARDS severity, ARDS etiology, sedation, $\mathrm{PaCO}_{2}$ during CVA assessment, prone position, inhalational nitric oxide, vvECMO) as fixed effects and patient as a random effect. The model was gradually reduced following a stepwisebackwards approach. Variables that caused a change in parameter estimates of $>10 \%$ or that were statistically significant $(p<0.05$, two-tailed hypotheses) remained in the model. The linearity between continuous variables was checked graphically with scatter plots. Residuals 
were graphically assessed for normal distribution using $\mathrm{Q}-\mathrm{Q}$ and residual plots. Additionally, we performed a leave-one-out cross-validation to evaluate the final model. As part of a sensitivity analysis, the model was recalculated with (1) a higher threshold for early hypercapnia $\left(\mathrm{PaCO}_{2} \geq 60 \mathrm{mmHg}\right.$ with a corresponding $\mathrm{pH}<7.35$ within the first $24 \mathrm{~h}$ of ARDS diagnosis) and (2) delta $\mathrm{PaCO}_{2}$ (the difference between ARDS diagnosis and CVA assessment).

An exploratory subgroup analysis was performed to compare CVA during measurements with and without vv-ECMO. In patients, who received vv-ECMO between two measurements, CVA was compared before and after vv-ECMO initiation.
All statistical analyses were performed with SPSS Version 24 (IBM SPSS Statistics, IBM Corporation). Figures were designed with Prism 8, Version 8.4.3 (GraphPad Software Inc., San Diego, CA, USA).

\section{Results}

\section{Patient characteristics}

Between December 2018 and November 2019, 70 patients were enrolled and 66 patients were included in the final analysis. Data from 2 patients, who died before a legal guardian was appointed or before they regained consciousness and ability to give informed consent, were destroyed and therefore not available for analysis. Legal guardians from two patients did not give consent to study

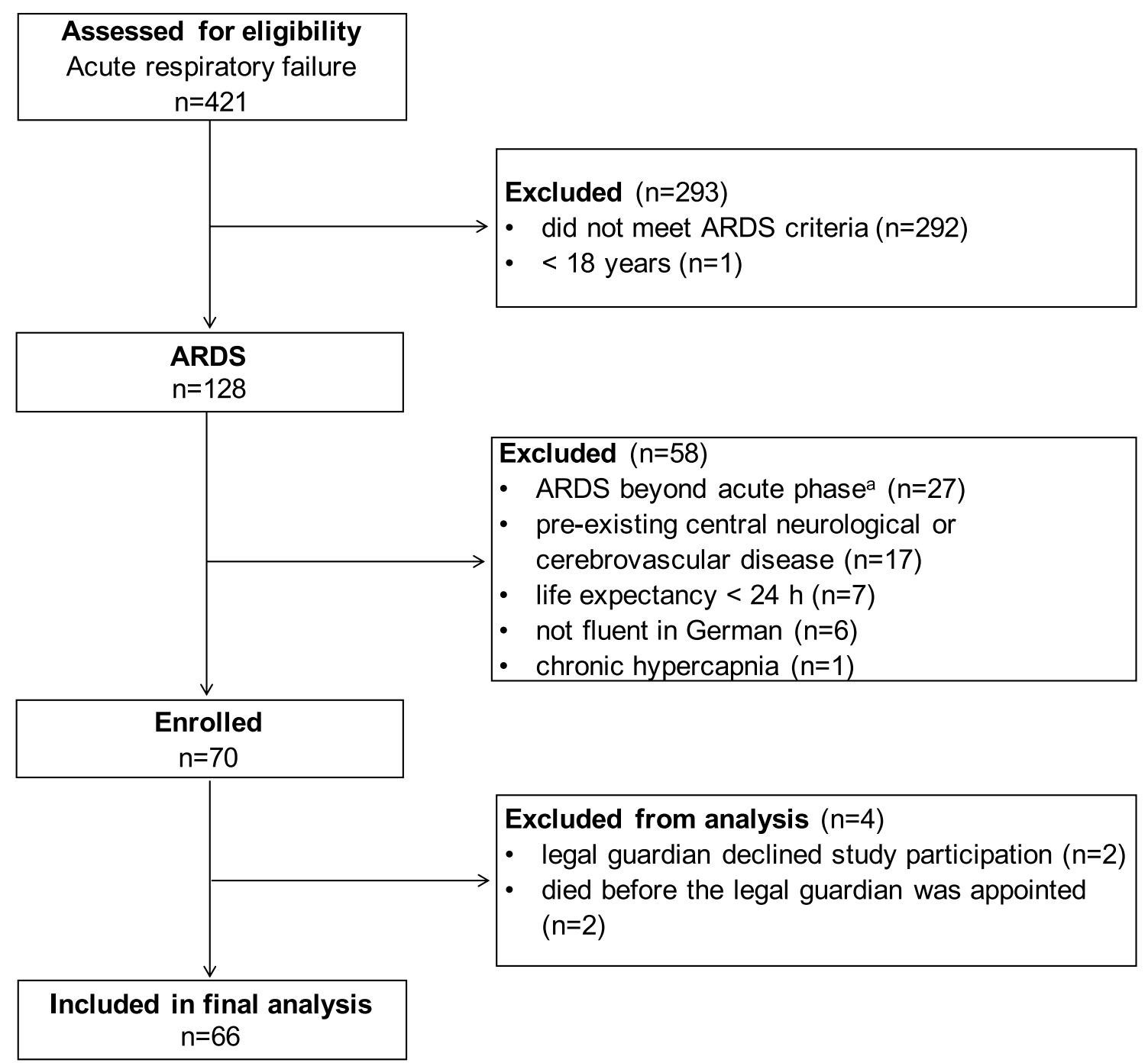

Fig. 1 Flowchart of patient selection and enrolment. ${ }^{a}>6$ days from the onset of acute respiratory distress syndrome (ARDS) 
participation. Data from the remaining patients were collected completely, so there are no missing values in our dataset. Figure 1 shows the flow of participants throughout the study.

The mean age of the study population was 58.5 years $( \pm 16) ; 14$ patients $(21.2 \%)$ were female. The majority of patients fulfilled the criteria for moderate $(n=28,42.4 \%)$ or severe $(n=28 ; 42.4 \%)$ ARDS. $\mathrm{PaO}_{2} / \mathrm{FiO}_{2}$ ratios and PEEP values for individual study participants are presented in Additional file 2. Etiologies of ARDS included pneumonia $(n=45,68.2 \%)$, extrapulmonary causes ( $n=12,18.2 \%)$, toxic lung injury $(n=3,4.5 \%)$, aspiration of gastric contents $(n=3 ; 4.5 \%)$ and unknown causes $(n=3,4.5 \%)$. Early hypercapnia was present in 39 of 66 patients (59.1\%). All patients required mechanical ventilation. Seven patients (10.6\%) were ventilated non-invasively. A total of 19 patients (28.8\%) received vv-ECMO. Baseline demographics, clinical characteristics and details on ARDS management stratified by the presence of early hypercapnia are presented in Table 1 . Data on new central nervous system disorders at discharge and functional outcome at 3 months are presented in Additional file 3.

\section{Early hypercapnia}

Cerebrovascular autoregulation was monitored twice in 51 of the 66 patients, and once in 15 patients, resulting in a total of 117 measurement periods. Patients with early hypercapnia showed impaired CVA during $22.95 \pm 18.75 \%$ of the monitoring period. In patients without early hypercapnia cerebrovascular autoregulatory response was impaired during $27.45 \pm 18.51 \%$ of the monitoring period (Fig. 2). Mean MAP $(74.9 \mathrm{mmHg} \pm 9.1$ vs. $76.3 \mathrm{mmHg} \pm 10.8)$ and mean COx $(0.06 \pm 0.18$ vs. $0.11 \pm 0.15)$ were similar in patients with and without early hypercapnia. Cerebral oxygenation was higher in patients with early hypercapnia $(67.32 \% \pm 10.20)$ compared with patients without early hypercapnia $(59.81 \% \pm 12.03)$. Patients with early hypercapnia had significantly higher mean $\mathrm{PaCO}_{2}$ $(47.8 \mathrm{mmHg} \pm 17.9$ vs. $41.6 \mathrm{mmHg} \pm 8.6, p=0.001)$ and higher $\mathrm{PaCO}_{2}$ variability $(115.1 \mathrm{mmHg} \pm 168.8$ vs. $32.1 \mathrm{mmHg} \pm 40.3, p<0.001$ ) between ARDS diagnosis and the first CVA assessment compared with patients without early hypercapnia; Table 2 . The evolution of $\mathrm{PaCO}_{2}$ between ARDS onset and CVA assessments is presented in Additional file 4. Additional data on hemodynamic parameters and results from arterial blood gas analyses are listed in Table 2.

Multivariable analysis did not show a significant association between early hypercapnia $\left(\mathrm{PaCO}_{2} \geq 50 \mathrm{mmHg}\right.$ with $\mathrm{pH}<7.35$ ) and impaired CVA (Table 3). In contrast to normo- and hypercapnia, hypocapnic episodes during measurement were significantly associated with impaired CVA $(B=0.155$ [95\% CI 0.014; 0.296], $p=0.032)$; Fig. 3. Other variables included in the model for a potentially confounding influence (vv-ECMO, sedation, ARDS severity, age, ARDS etiology) were not significantly associated with impaired CVA (Table 3 and Additional file 5).

The sensitivity analysis did not show a significant association between early hypercapnia $\left(\mathrm{PaCO}_{2} \geq 60 \mathrm{mmHg}\right)$ and impaired CVA (Additional file 6a). In contrast to normo- and hypercapnia, hypocapnic episodes during measurement were significantly associated with impaired CVA ( $B=0.186$ [95\% CI 0.072; 0.300], $p=0.002)$. Other variables included in the model for a potentially confounding influence (age and ARDS etiology) were not significantly associated with impaired CVA (Additional file 6a).

To assess the potential effect of $\mathrm{PaCO}_{2}$ changes on CVA impairment, we used another linear mixed model with the difference in $\mathrm{PaCO}_{2}$ between ARDS diagnosis and the time of CVA assessment (Additional file 6b). There was no significant association of the delta $\mathrm{PaCO}_{2}$ with impaired CVA. Compared with normo- and hypercapnia, hypocapnia during CVA measurement was significantly associated with impaired CVA.

\section{Extracorporeal membrane oxygenation}

Cerebrovascular autoregulation was compared between 19 patients with vv-ECMO, and 47 patients without vv-ECMO. Mean COx and the time with impaired CVA were similar between vv-ECMO and non-ECMO patients (Additional file 7). Patients with vv-ECMO had higher cerebral oxygenation $\left(\mathrm{rSO}_{2}=67.32 \% \pm 10.96\right)$ than patients without vv-ECMO $\left(\mathrm{rSO}_{2}=63.21 \% \pm 11.6\right)$. In seven patients, who received vv-ECMO during the course of the disease, CVA was measured before and after vvECMO initiation. Results from these paired monitoring episodes are shown in Additional file 8.

\section{Discussion}

The aim of this prospective observational study was to compare CVA during the acute phase of ARDS between patients with and without early hypercapnia. We found that early hypercapnia was not associated with impaired CVA. However, we observed a significant association between hypocapnia during the acute phase of ARDS and impaired CVA.

Early hypercapnia has been shown to be associated with adverse outcome after ARDS [8, 9]. Previous clinical trials that investigated CVA in ARDS focused primarily on the influence of PEEP rather than $\mathrm{CO}_{2}[26,27]$. While Yang et al. did not specifically address the cerebrovascular effects of $\mathrm{PaCO}_{2}$, Schramm et al. reported 
Table 1 Baseline demographic and clinical characteristics and details on the management of acute respiratory distress syndrome (ARDS)

\begin{tabular}{|c|c|c|c|}
\hline & No early hypercapnia $(n=27)$ & Early hypercapnia $(n=39)$ & $p$ \\
\hline Age, years & $62 \pm 17$ & $55 \pm 15$ & 0.040 \\
\hline Gender (female) & $5(18.5)$ & $9(23.1)$ & 0.765 \\
\hline Body mass index & $26.8 \pm 4.4$ & $30.8 \pm 11.3$ & 0.334 \\
\hline \multicolumn{4}{|l|}{ Comorbid conditions } \\
\hline Arterial hypertension & $10(37.0)$ & $16(41.0)$ & 0.802 \\
\hline Diabetes & $1(3.7)$ & $8(20.5)$ & 0.071 \\
\hline Coronary heart disease & $3(11.1)$ & $7(17.9)$ & 0.508 \\
\hline Arrhythmia & $7(25.9)$ & $3(7.7)$ & 0.077 \\
\hline Chronic obstructive pulmonary disease ${ }^{a}$ & $2(7.4)$ & $6(15.4)$ & 0.455 \\
\hline Asthma & $0(0.0)$ & $2(5.1)$ & 0.509 \\
\hline Malignant hematooncologic disease & $7(25.9)$ & $3(7.7)$ & 0.077 \\
\hline Autoimmune disease & $3(11.1)$ & $2(5.1)$ & 0.393 \\
\hline Solid organ transplantation & $2(7.4)$ & $2(5.1)$ & 1.000 \\
\hline AIDS & $0(0.0)$ & $1(2.6)$ & 1.000 \\
\hline ARDS severity & & & 0.397 \\
\hline Mild & $4(14.8)$ & $6(15.4)$ & \\
\hline Moderate & $14(51.9)$ & $14(35.9)$ & \\
\hline Severe & $9(33.3)$ & $19(48.7)$ & \\
\hline ARDS etiology & & & 0.136 \\
\hline Community-acquired pneumonia & $9(33.3)$ & $19(48.7)$ & \\
\hline Hospital-acquired pneumonia & $11(40.7)$ & $6(15.4)$ & \\
\hline Aspiration & $1(3.7)$ & $2(5.1)$ & \\
\hline Toxic & $2(7.4)$ & $1(2.6)$ & \\
\hline Extrapulmonary & $4(14.8)$ & $8(20.5)$ & \\
\hline Unknown & $0(0.0)$ & $3(7.7)$ & \\
\hline ARDS etiology & & & 0.020 \\
\hline Community-acquired & $12(44.4)$ & $29(74.4)$ & \\
\hline Hospital-acquired & $15(55.5)$ & $10(25.6)$ & \\
\hline SOFA score ${ }^{b}$ & $9 \pm 4$ & $10 \pm 3$ & 0.854 \\
\hline \multicolumn{4}{|l|}{ Mechanical ventilation } \\
\hline Non-invasive ventilation & $7(25.9)$ & $0(0.0)$ & $<0.001$ \\
\hline Invasive ventilation & $20(74.1)$ & $39(100)$ & \\
\hline Respiratory rate, breaths per min & $25 \pm 5$ & $21 \pm 6$ & $<0.001$ \\
\hline Tidal volume, $\mathrm{ml}$ & $434 \pm 185$ & $395 \pm 133$ & 0.485 \\
\hline Difference from ideal tidal volume ${ }^{c}, \mathrm{ml}$ & $19 \pm 192$ & $-36 \pm 142$ & 0.264 \\
\hline Positive end-expiratory pressure, mbar & $10 \pm 4$ & $13 \pm 4$ & 0.001 \\
\hline Driving pressure, mbar & $15 \pm 4$ & $14 \pm 3$ & 0.231 \\
\hline Sedation & & & 0.048 \\
\hline Intravenous $^{\mathrm{d}}$ & $13(48.1)$ & $17(43.6)$ & \\
\hline Inhalational ${ }^{\mathrm{e}}$ & $0(0.0)$ & $2(5.1)$ & \\
\hline Mixed $^{f}$ & $10(37.0)$ & $20(51.3)$ & \\
\hline None & $4(14.8)$ & $0(0.0)$ & \\
\hline \multicolumn{4}{|l|}{ Adjunctive therapy } \\
\hline Prone position & $11(40.7)$ & $14(35.9)$ & 0.798 \\
\hline Inhaled nitric oxide & $6(22.2)$ & $9(23.1)$ & 1.000 \\
\hline Veno-venous ECMO & $3(11.1)$ & $16(41.0)$ & 0.012 \\
\hline
\end{tabular}

Data are given in $n(\%)$ or mean \pm SD

ECMO extracorporeal membrane oxygenation

a Without chronic hypercapnia

b Highest score during measurement of cerebrovascular autoregulation

c Ideal tidal volume was defined as $6 \mathrm{ml} / \mathrm{kg}$ of ideal body weight

d Continuous administration of propofol or midazolam

e Inhalational application of isoflurane

${ }^{f}$ Propofol plus isoflurane or midazolam plus isoflurane 


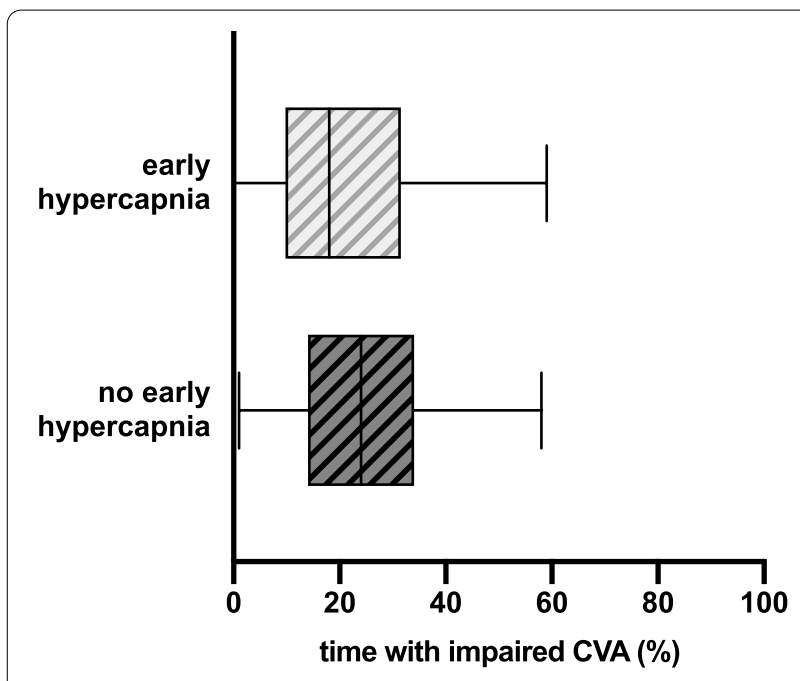

Fig. 2 Early hypercapnia and cerebrovascular autoregulation. Shows the time with impaired cerebrovascular autoregulation (CVA; in \% of the total monitoring time) in ARDS patients with early hypercapnia vs. no early hypercapnia. The COx was depicted as a moving linear correlation based on mean arterial pressure and cerebral oxygenation (ICM+, Cambridge Enterprise, Cambridge, UK). Impaired cerebrovascular autoregulation was defined as a $C O x>0.3$. ARDS Acute respiratory distress syndrome, COx cerebral oxygenation index. Data are presented as median (boxes) with Tukey whiskers

that hypercapnia was not associated with impaired CVA, which is similar to our results.

We found that hypocapnia during measurement was associated with impaired CVA. Interestingly, in a large retrospective registry analysis, Cavayas et al. found the rate of $\mathrm{PaCO}_{2}$ reduction upon ECMO initiation to be associated with neurological complications in patients with severe respiratory failure [10]. The risk for ischemic stroke, intracerebral hemorrhage, seizures, and brain death increased with the magnitude of $\mathrm{PaCO}_{2}$ correction within $24 \mathrm{~h}$ after ECMO initiation [10]. Similar results were reported in a retrospective single-center study [28]. In 135 patients on vv-ECMO for severe respiratory failure, rapid correction of hypercapnia was associated with intracranial bleeding [28]. We did not find a significant association of the difference in $\mathrm{PaCO}_{2}$ between ARDS diagnosis and CVA assessment and impaired CVA. However, we did not analyze the effect of hypercapnia reduction on CVA.

There are conflicting results on the effect of hypocapnia on CVA in pathologies other than ARDS. While hypocapnia has been shown to promote the impairment of CVA in patients with acute brain injury [29], other studies found no adverse effect of transient hypocapnia on CVA in healthy adults and other neurocritical care patients [30-33].

When interpreting the conflicting results on the effects of $\mathrm{CO}_{2}$ on CVA, it is important to differentiate between the diverse patient populations, as well as different definitions of hypo-, normo- and hypercapnia. This may limit the generalizability of results from single trials. Furthermore, the duration of hyperand hypocapnia has to be considered when analyzing potential effects of $\mathrm{CO}_{2}$ on CVA. In patients with ARDS, alterations of $\mathrm{PaCO}_{2}$ are mainly driven by respiratory failure or ventilation strategies including low tidal volumes and permissive hypercapnia. Due to our strictly observational study design, we did not actively change $\mathrm{PaCO}_{2}$. Therefore, hyper- or hypocapnia had been present for a period of several hours up to 6 days before measurement. In contrast, studies in healthy subjects and neurocritical care patients included interventional modifications of ventilator settings or spontaneous inhalation of $\mathrm{CO}_{2}[29,31,33]$. In these trials, there was little time delay between reaching the target $\mathrm{PaCO}_{2}$ and the measurement of CVA. Muizelaar et al. observed that the vasoconstrictive effect of hyperventilation decreases over time. They showed that cerebral vessels returned to their baseline diameter after $20 \mathrm{~h}$ of hyperventilation [34]. One can assume that the effects of $\mathrm{CO}_{2}$ on vascular tone become apparent early after elevation or reduction of $\mathrm{PaCO}_{2}$ and that the cerebral vasculature adapts to intermediate or long-term alterations of $\mathrm{PaCO}_{2}$.

In our study, almost $60 \%$ of patients presented with early hypercapnia, which is higher than reported previously [9]. Notably, Nin et al. found a $22 \%$ prevalence of early hypercapnia in patients with ARDS [9]. The different prevalence may be caused by two main factors: we defined early hypercapnia within the first $24 \mathrm{~h}$ of ARDS diagnosis, while Nin et al. assessed hypercapnia during the first $48 \mathrm{~h}$ of mechanical ventilation [9]. Importantly, we used protective ventilation with tidal volumes of $\leq 6 \mathrm{ml} / \mathrm{kg}$ of IBW. In contrast, Nin et al. performed a secondary analysis of data from three clinical trials that were published between 2002 and 2013 [35-37]. Mean tidal volumes in these trials were substantially higher with up to $10 \mathrm{ml} / \mathrm{kg}$ of IBW, probably reflecting the gradual implementation of the concept of low tidal volumes and permissive hypercapnia into clinical practice.

We observed higher cerebral oxygenation in patients with early hypercapnia compared to patients without early hypercapnia. This finding might be attributable to the vasodilatory effect of $\mathrm{CO}_{2}$ leading to an increase in cerebral blood flow and cerebral tissue oxygenation [11]. Of note, patients with early hypercapnia received sedation with isoflurane more frequently. Volatile anesthetics such as isoflurane are characterized by cerebral vasodilatory properties that may contribute to higher cerebral oxygenation in patients with early hypercapnia [38]. 
Table 2 Hemodynamic parameters and selected results from blood gas analyses during the measurement of cerebrovascular autoregulation (CVA)

\begin{tabular}{|c|c|c|}
\hline & $\begin{array}{l}\text { No early hypercapnia }(n=27) \\
\text { Measurement periods }=47\end{array}$ & $\begin{array}{l}\text { Early hypercapnia }(n=39) \\
\text { Measurement periods }=70\end{array}$ \\
\hline Time with impaired CVA (\%) & $27.45 \pm 18.51$ & $22.95 \pm 18.75$ \\
\hline Duration of measurement (min) & $77 \pm 12$ & $77 \pm 15$ \\
\hline Time with impaired CVA (min) & $21 \pm 15$ & $18 \pm 15$ \\
\hline Cerebral oxygenation index COx & $0.11 \pm 0.15$ & $0.06 \pm 0.18$ \\
\hline Regional cerebral oxygen saturation $\mathrm{rSO}_{2}(\%)$ & $59.81 \pm 12.03$ & $67.32 \pm 10.20$ \\
\hline Mean arterial blood pressure $(\mathrm{mmHg})$ & $76.34 \pm 10.84$ & $74.85 \pm 9.12$ \\
\hline Heart rate (bpm) & $81.25 \pm 18.80$ & $90.45 \pm 19.10$ \\
\hline Body temperature $\left({ }^{\circ} \mathrm{C}\right)$ & $37.1 \pm 0.8$ & $37.1 \pm 0.9$ \\
\hline Hemoglobin $\left(\mathrm{mg} \mathrm{dl}^{-1}\right)$ & $9.20 \pm 1.42$ & $9.79 \pm 1.63$ \\
\hline $\mathrm{PaO}_{2} / \mathrm{FiO}_{2}$ ratio & $152.55 \pm 57.16$ & $151.38 \pm 75.27$ \\
\hline Mean $\mathrm{PaO}_{2}(\mathrm{mmHg})$ & $80.6 \pm 18.4$ & $85.9 \pm 16.4$ \\
\hline Mean $\mathrm{PaCO}_{2}(\mathrm{mmHg})^{\mathrm{a}}$ & $45.2 \pm 11.1$ & $47.7 \pm 9.6$ \\
\hline Hypocapnia $(<35 \mathrm{mmHg})^{\text {b }}$ & $8(17)$ & $3(4.3)$ \\
\hline Normocapnia (35-50 mmHg) ${ }^{b}$ & $28(59.6)$ & $43(61.4)$ \\
\hline Hypercapnia $(>50 \mathrm{mmHg})^{b}$ & $11(23.4)$ & $24(34.3)$ \\
\hline $\mathrm{pH}$ & $7.41 \pm 0.08$ & $7.39 \pm 0.09$ \\
\hline Lactate (mmol/L) & $1.6 \pm 0.9$ & $2.3 \pm 2.5$ \\
\hline$\triangle \mathrm{PaCO}_{2}(\mathrm{mmHg})^{\mathrm{c}}$ & $1.29 \pm 1.76$ & $1.79 \pm 3.23$ \\
\hline$\Delta \mathrm{pH}^{\mathrm{c}}$ & $0.01 \pm 0.02$ & $0.01 \pm 0.02$ \\
\hline$\Delta \mathrm{PaO}_{2} / \mathrm{FiO}_{2}$ ratio $(\mathrm{mmHg})^{\mathrm{c}}$ & $8.20 \pm 12.86$ & $9.86 \pm 19.73$ \\
\hline Isoflurane $(\mathrm{ml} / \mathrm{h})$ & $6.5 \pm 4.5$ & $6.8 \pm 4.1$ \\
\hline Isoflurane (end-tidal concentration in \%) & $1.1 \pm 0.4$ & $1.2 \pm 0.3$ \\
\hline \multicolumn{3}{|l|}{ From ARDS diagnosis until first CVA measurement } \\
\hline Time from ARDS diagnosis to first measurement (days) & $4 \pm 4$ & $2 \pm 2$ \\
\hline Mean $\mathrm{PaCO}_{2}(\mathrm{mmHg})$ & $41.6 \pm 8.6$ & $47.8 \pm 17.9$ \\
\hline $\mathrm{PaCO}_{2}$ variability $^{\mathrm{d}}(\mathrm{mmHg})$ & $32.1 \pm 40.3$ & $115.1 \pm 168.8$ \\
\hline \multicolumn{3}{|l|}{ From first until second CVA measurement } \\
\hline Time from ARDS diagnosis to second measurement (days) & $8 \pm 3$ & $5 \pm 3$ \\
\hline Mean $\mathrm{PaCO}_{2}(\mathrm{mmHg})$ & $49.2 \pm 10.9$ & $49.0 \pm 7.3$ \\
\hline $\mathrm{PaCO}_{2}$ variability ${ }^{\mathrm{d}}(\mathrm{mmHg})$ & $68.6 \pm 65.2$ & $57.8 \pm 50.2$ \\
\hline
\end{tabular}

Mean values from monitoring episodes 1 and 2, stratified by the presence of early hypercapnia. Data are given in $n(\%)$ or mean \pm SD

COx cerebral oxygenation index as a surrogate of cerebrovascular autoregulation

a "Mean $\mathrm{PaCO}_{2}$ " refers to the statistical mean of two blood gas analyses during one CVA monitoring episode

b $\mathrm{PaCO}_{2}$ was categorized as "hypocapnia”, "normocapnia”, and "hypercapnia” during each measurement period

c $\Delta$ values refer to the mean difference between the first and the second CVA measurement in one study participant

d Calculated as the variance

Our study was primarily designed to assess the effect of early hypercapnia on CVA in patients with ARDS. It is important to note that $\mathrm{CO}_{2}$ does not only influence cerebral vascular tone, but also other organ systems. Among others, hyper- and hypocapnia are associated with the severity of respiratory failure, compromised immune response, and impaired right ventricular function $[8,39]$.

\section{Limitations and strengths}

There are several limitations to this observational trial. First, spontaneously breathing patients without sedation were more likely to have higher respiratory rates and lower $\mathrm{PaCO}_{2}$. We did consider the type of sedation as a potential confounder in the multivariable analysis and did not find a significant association between type of sedation and CVA. However, anesthetics are known to affect 
Table 3 Linear mixed model_estimates of fixed effects

\begin{tabular}{|c|c|c|c|c|}
\hline Parameter & Estimate & $95 \% \mathrm{Cl}$-low & $95 \% \mathrm{Cl}$-up & p \\
\hline Intercept & 0.177 & -0.059 & 0.414 & 0.139 \\
\hline No early hypercapnia (vs. early hypercapnia $=\mathrm{PaCO}_{2} \geq 50 \mathrm{mmHg}$ ) & 0.023 & -0.054 & 0.100 & 0.556 \\
\hline \multicolumn{5}{|l|}{ Sedation } \\
\hline Mixed sedation (vs. no sedation) & -0.042 & -0.217 & 0.133 & 0.635 \\
\hline Intravenous sedation (vs. no sedation) & -0.074 & -0.235 & 0.087 & 0.363 \\
\hline Inhalational sedation (vs. no sedation) & -0.076 & -0.260 & 0.107 & 0.410 \\
\hline \multicolumn{5}{|l|}{ ARDS severity } \\
\hline Mild (vs. severe) & 0.032 & -0.062 & 0.126 & 0.498 \\
\hline Moderate (vs. severe) & -0.018 & -0.102 & 0.065 & 0.663 \\
\hline Age (per year increase) & 0.001 & -0.001 & 0.004 & 0.275 \\
\hline Hypocapnia during the measurement period ${ }^{a}$ & 0.155 & 0.014 & 0.296 & 0.032 \\
\hline ARDS etiology (community-acquired vs. hospital-acquired) ${ }^{b}$ & 0.047 & -0.027 & 0.122 & 0.208 \\
\hline
\end{tabular}

The variables position (prone vs. supine), inhalational nitric oxide, extracorporeal membrane oxygenation, and the Sequential Organ Failure Assessment score during measurement were included in the initial model and eliminated during the stepwise-backwards reduction

ARDS: acute respiratory distress syndrome

a Vs. Normo- and hypercapnia

b Etiologies were categorized as "community-acquired" and "hospital-acquired" for the linear mixed model

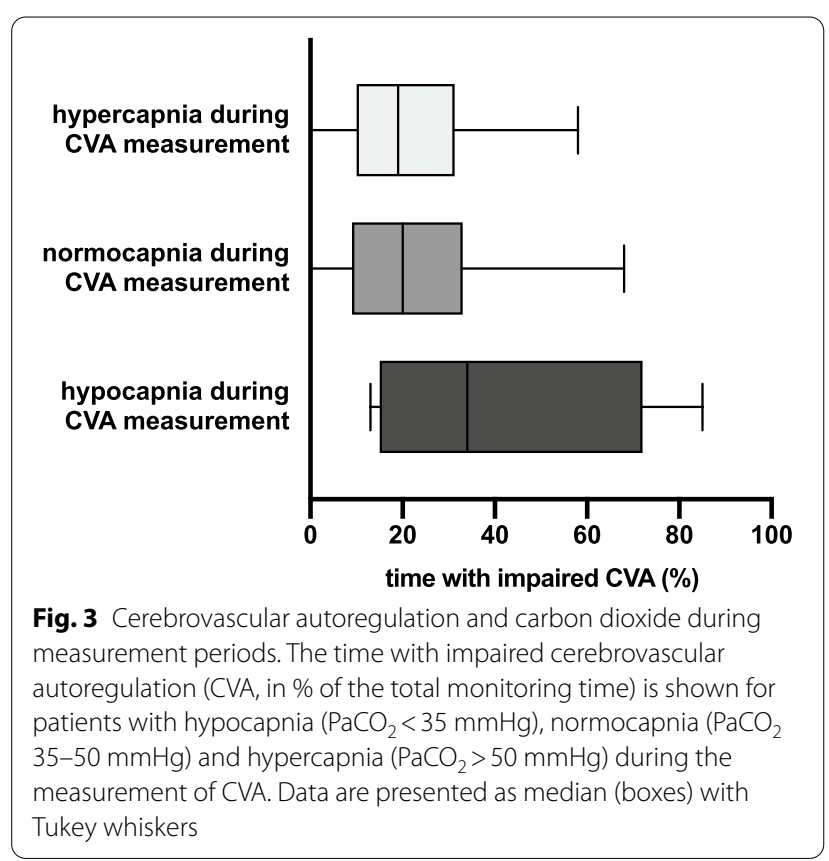

cerebrovascular tone as well as CVA. We cannot rule out that a statistical effect did not become apparent because of our relatively small sample size. The same applies for vv-ECMO therapy, which was not significantly associated with impaired CVA in our study. Importantly, the impact of vv-ECMO on CVA remains unclear [40]. Having said that, it is noteworthy that we used veno-venous flow in all patients requiring ECMO, which is supposed to have less impact on cerebral blood flow than ECMO with veno-arterial flow [41].
Second, there are several methods for the continuous measurement of CVA that differ with regard to the assessment of cerebral blood flow. Non-invasive approaches include transcranial Doppler sonography and near-infrared spectroscopy [24]. We chose the latter approach, which has been validated thoroughly [42, 43]. However, differences in methodological approaches lead to a limited comparability between study results. We continuously analyzed CVA during a 60-90 min period during the acute phase of ARDS. $\mathrm{PaCO}_{2}$ was determined twice during CVA assessment. There were no substantial fluctuations of $\mathrm{PaCO}_{2}$ during CVA monitoring. However, we observed a high variability of $\mathrm{PaCO}_{2}$ between the diagnosis of ARDS and CVA assessment that was significantly higher in patients with early hypercapnia. By choosing CVA assessment within predefined time periods of 60-90 min, we may have missed relevant fluctuations of $\mathrm{PaCO}_{2}$. This limitation highlights the need for future studies using continuous CVA monitoring throughout the course of disease.

Two-channel near-infrared spectroscopy used in this study provides information on cerebral oxygenation in the area of the frontal cortex. Oxygenation of other cerebral lobes and deeper brain structures is not reflected by near-infrared spectroscopy [44].

Third, volatile anesthetics including isoflurane may have a profound effect on cerebrovascular tone resulting in a substantial impact on CVA [45]. Although we have included the type of sedation as a potential confounder in the multivariable analysis, the cerebrovascular effects of isoflurane may have biased the results of our study. 
Since the definition of hypercapnia varies between studies, we performed a sensitivity analysis using a higher threshold for early hypercapnia $\left(\mathrm{PaCO}_{2} \geq 60 \mathrm{mmHg}\right)$. This confirmed our initial findings and did not reveal an association between early hypercapnia and impaired CVA. Impairment of CVA has been linked with poor neurocognitive outcome and mortality in patients without structural central nervous system lesions [14, 43]. This study focused on the association between alterations of $\mathrm{PaCO}_{2}$ during the acute phase of ARDS and CVA. Future research should assess the effect on CVA impairment on functional neurological outcome after ARDS.

\section{Conclusions}

In the present study, we did not observe an adverse impact of hypercapnia during the acute phase of ARDS on CVA. However, we found that hypocapnia is associated with impaired CVA. Our findings suggest that moderate hypercapnia during the acute phase of ARDS may be safe with regard to CVA and hypercapnia may be tolerated to a certain extent to achieve low tidal volumes, whereas episodes of hypocapnia may compromise cerebral blood flow regulation.

\section{Abbreviations}

ARDS: Acute respiratory distress syndrome; $\mathrm{CO}_{2}$ : Carbon dioxide; $\mathrm{COx}$ : Cerebral oxygenation index; CVA: Cerebrovascular autoregulation; vv-ECMO: Veno-venous extracorporeal membrane oxygenation; IBW: Ideal body weight; MAP: Mean arterial blood pressure; $\mathrm{PaCO}_{2}$ : Arterial partial pressure of carbon dioxide.

\section{Supplementary Information}

The online version contains supplementary material available at https://doi. org/10.1186/s13613-021-00831-7.

Additional file 1. ARDS management. Informed consent procedure, ARDS diagnosis, and ARDS management throughout the study period.

Additional file 2. $\mathrm{PaO}_{2} / / \mathrm{FiO}_{2}$ ratio and PEEP for ARDS diagnosis. $\mathrm{PaO}_{2} /$ $\mathrm{FiO}_{2}$ ratio and positive end-exspiratory pressure (PEEP) in individual study participants.

Additional file 3. CVA and functional outcome. Neuroimaging, new CNS disorders, and functional outcome at three months.

Additional file 4. Development of arterial carbon dioxide. $\mathrm{PaCO} 2$ from the diagnosis of ARDS until first CVA assessment and between first and second CVA assessments, stratified by the presence of early hypercapnia.

Additional file 5. Linear mixed model including preselected variables of clinical relevance. Initial linear mixed model. All variables included were selected based on clinical considerations.

Additional file 6. Sensitivity analysis. 6a-Linear mixed model with an alternative definition of early hypercapnia $\left(\mathrm{PaCO}_{2} \geq 60 \mathrm{mmHg}\right.$ with $\mathrm{pH}<7.35$ ). $6 \mathrm{~b}$ - Linear mixed model with delta $\mathrm{PaCO} 2$ (difference between ARDS diagnosis and CVA measurements) as independent variable.

Additional file 7. CVA in patients with and without ECMO. 7a-Hemodynamic parameters and selected results from blood gas analyses in patients requiring extracorporeal membrane oxygenation (ECMO) and patients without ECMO. Mean values from monitoring episodes 1 and 2 are presented, stratified by the requirement of veno-venous ECMO. Data are given as mean \pm SD. COx: cerebral oxygenation index representing cerebrovascular autoregulation (CVA). $\mathrm{SSO}_{2}$ : cerebral oxygenation measured with near-infrared spectroscopy. MAP: mean arterial blood pressure. $7 \mathrm{~b}$-Time with impaired CVA between 19 patients with veno-venous $\mathrm{ECMO}$, and 47 patients without ECMO.

Additional file 8. Repeated CVA measurements in 7 patients with and without ECMO. 8a-Repeated measurement episodes of cerebrovascular autoregulation (CVA) with and without extracorporeal membrane oxygenation (ECMO) in 7 patients. Data are given as mean \pm SD. COx: cerebral oxygenation index as a surrogate of $\mathrm{CVA}$. $\mathrm{rSO}_{2}$ : cerebral oxygenation measured with near-infrared spectroscopy. 8b-Time with impaired CVA in repeated measurements with and without ECMO.

\section{Acknowledgements}

Not applicable.

\section{Authors' contributions}

UK: conception and design of the work; acquisition, analysis, and interpretation of data; writing original draft. YY: acquisition, analysis, and interpretation of data; substantial revision of the manuscript. AN: design of the work; interpretation of data; substantial revision of the manuscript. DF: design of the work; acquisition, analysis, and interpretation of data; substantial revision of the manuscript. BS: acquisition, analysis, and interpretation of data. AD: design of the work; analysis, and interpretation of data; substantial revision of the manuscript. SK: conception and design of the work; interpretation of data; substantial revision of the manuscript. MF: conception and design of the work; acquisition, analysis, and interpretation of data; writing original draft. All authors have approved the submitted version (and any substantially modified version that involves the author's contribution to the study), and have agreed both to be personally accountable for the author's own contributions and to ensure that questions related to the accuracy or integrity of any part of the work, even ones in which the author was not personally involved, are appropriately investigated, resolved, and the resolution documented in the literature. All authors read and approved the final manuscript.

\section{Funding}

Open Access funding enabled and organized by Projekt DEAL. Ursula Kahl is funded by the Clinician Scientist Program of the University of Hamburg. The University of Hamburg was not involved in any of the following: study design, conduct of the research, preparation of this manuscript, analysis and interpretation of data; writing of the report; decision to submit the article for publication.

Marlene Fischer receives financial support from the Johanna und Fritz Buch Gedächtnis-Stiftung. The Johanna und Fritz Buch Gedächtnis-Stiftung was not involved in any of the following: study design, conduct of the research, preparation of this manuscript, analysis and interpretation of data; writing of the report; decision to submit the article for publication.

\section{Availability of data and materials}

The datasets used and analyzed during the current study are available from the corresponding author on reasonable request.

\section{Declarations}

\section{Ethics approval and consent to participate}

Ethical approval for this study (serial number PV5872) was obtained from the ethics committee of the Hamburg Chamber of Physicians on November 8th, 2018. Oral and written informed consent were obtained from the patient or legal guardian.

\section{Consent for publication \\ Not applicable.}

\section{Competing interests}

The authors declare that they have no competing interests. 


\section{Author details}

${ }^{1}$ Department of Anesthesiology, University Medical Center Hamburg-Eppendorf, Martinistrasse 52, 20246 Hamburg, Germany. ${ }^{2}$ Department of Intensive Care Medicine, University Medical Center Hamburg-Eppendorf, Hamburg, Germany. ${ }^{3}$ Institute of Medical Biometry and Epidemiology, University Medical Center Hamburg-Eppendorf, Hamburg, Germany.

Received: 29 November 2020 Accepted: 1 March 2021

Published online: 16 March 2021

\section{References}

1. ARDS Definition Task Force. Acute respiratory distress syndrome: the berlin definition. J Am Med Assoc. 2012;307:2526-33.

2. Bellani G, Laffey JG, Pham T, Fan E, Brochard L, Esteban A, et al. Epidemiology, patterns of care, and mortality for patients with acute respiratory distress syndrome in intensive care units in 50 countries. JAMA 2016;315:788.

3. Bein T, Weber-Carstens S, Apfelbacher C. Long-term outcome after the acute respiratory distress syndrome: different from general critical illness? Curr Opin Crit Care. 2018;24:35-40.

4. Hickling KG, Henderson SJ, Jackson R. Low mortality associated with low volume pressure limited ventilation with permissive hypercapnia in severe adult respiratory distress syndrome. Intensive Care Med. 1990;16:372-7.

5. Amato MB, Barbas CS, Medeiros DM, Magaldi RB, Schettino GP, LorenziFilho $\mathrm{G}$, et al. Effect of a protective-ventilation strategy on mortality in the acute respiratory distress syndrome. N Engl J Med. 1998;338:347-54.

6. Briva A, Vadász I, Lecuona E, Welch LC, Chen J, Dada LA, et al. High CO2 levels impair alveolar epithelial function independently of pH. PLOS ONE. 2007;2:e1238.

7. Doerr CH, Gajic O, Berrios JC, Caples S, Abdel M, Lymp JF, et al. Hypercapnic acidosis impairs plasma membrane wound resealing in ventilatorinjured lungs. Am J Respir Crit Care Med. 2005;171:1371-7.

8. Morales-Quinteros L, Camprubí-Rimblas M, Bringué J, Bos LD, Schultz MJ, Artigas A. The role of hypercapnia in acute respiratory failure. Intensive Care Med Exp. 2019;7:39.

9. Nin N, Muriel A, Peñuelas O, Brochard L, Lorente JA, Ferguson ND, et al. Severe hypercapnia and outcome of mechanically ventilated patients with moderate or severe acute respiratory distress syndrome. Intensive Care Med. 2017:43:200-8.

10. Cavayas YA, Munshi L, Del Sorbo L, Fan E. The early change in PaCO2 after extracorporeal membrane oxygenation initiation is associated with neurological complications. Am J Respir Crit Care Med. 2020;201:1525-35.

11. Meng L, Gelb AW. Regulation of cerebral autoregulation by carbon dioxide. Anesthesiology. 2015;122:196-205.

12. Lassen NA. Cerebral blood flow and oxygen consumption in man. Physiol Rev. 1959:39:183-238.

13. Donnelly J, Budohoski KP, Smielewski P, Czosnyka M. Regulation of the cerebral circulation: bedside assessment and clinical implications. Crit Care. 2016;20:129.

14. Crippa IA, Subirà C, Vincent J-L, Fernandez RF, Hernandez SC, Cavicchi FZ, et al. Impaired cerebral autoregulation is associated with brain dysfunction in patients with sepsis. Crit Care Lond Engl. 2018;22:327.

15. Rivera-Lara L, Zorrilla-Vaca A, Geocadin R, Ziai W, Healy R, Thompson R, et al. Predictors of outcome with cerebral autoregulation monitoring: a systematic review and meta-analysis. Crit Care Med. 2017;45:695-704.

16. Goodson CM, Rosenblatt K, Rivera-Lara L, Nyquist P, Hogue CW. Cerebral blood flow autoregulation in sepsis for the intensivist: why its monitoring may be the future of individualized care. J Intensive Care Med. 2018:33:63-73.

17. Fan E, Del Sorbo L, Goligher EC, Hodgson CL, Munshi L, Walkey AJ, et al. An Official American Thoracic Society/European Society of Intensive Care Medicine/Society of Critical Care Medicine Clinical Practice Guideline: mechanical ventilation in adult patients with acute respiratory distress syndrome. Am J Respir Crit Care Med. 2017;195:1253-63.

18. Fichtner F, Moerer O, Weber-Carstens S, Nothacker M, Kaisers U, Laudi $S$, et al. Clinical guideline for treating acute respiratory insufficiency with invasive ventilation and extracorporeal membrane oxygenation: evidence-based recommendations for choosing modes and setting parameters of mechanical ventilation. Respir Int Rev Thorac Dis. 2019;98:357-72.

19. Karagiannidis C, Bein T, Weber-Carstens S. Indications and limitations of ECMO therapy: considerations on evidence, treatment decisions and ethical challenges. Med Klin Intensivmed Notfallmedizin. 2019;114:207-13.

20. Arbeitsgemeinschaft der Wissenschaftlichen Medizinischen Fachgesellschaften (AWMF), Deutsche Gesellschaft für Anästhesiologie und Intensivmedizin (DGAl). S3-Leitlinie Invasive Beatmung und Einsatz extrakorporaler Verfahren bei akuter respiratorischer Insuffizienz. AWMF Leitlinien-Regist Nr 001021. 2017.

21. Matthay MA, Zemans RL. The acute respiratory distress syndrome: pathogenesis and treatment. Annu Rev Pathol. 2011;6:147-63.

22. Beck S, Ragab H, Hoop D, Meßner-Schmitt A, Rademacher C, Kahl U, et al. Comparing the effect of positioning on cerebral autoregulation during radical prostatectomy - a prospective observational study. J Clin Monit Comput. 2020. https://doi.org/10.1007/s10877-020-00549-0.

23. Xiong L, Liu X, Shang T, Smielewski P, Donnelly J, Guo Z, et al. Impaired cerebral autoregulation: measurement and application to stroke. J Neurol Neurosurg Psychiatry. 2017;88:520-31

24. Zweifel C, Dias C, Smielewski P, Czosnyka M. Continuous time-domain monitoring of cerebral autoregulation in neurocritical care. Med Eng Phys. 2014;36:638-45.

25. Hori D, Brown C, Ono M, Rappold T, Sieber F, Gottschalk A, et al. Arterial pressure above the upper cerebral autoregulation limit during cardiopulmonary bypass is associated with postoperative delirium. Br J Anaesth. 2014;113:1009-17.

26. Schramm P, Closhen D, Felkel M, Berres M, Klein KU, David M, et al. Influence of PEEP on cerebral blood flow and cerebrovascular autoregulation in patients with acute respiratory distress syndrome. J Neurosurg Anesth. 2013;25:162-7.

27. Yang $C$, Chen Z, Lu Y, He H, Zeng W. The influence of positive end-expiratory pressure on cerebral blood flow and cerebrovascular autoregulation in patients with acute respiratory distress syndrome. Zhonghua Wei Zhong Bing Ji Jiu Yi Xue. 2014;26:335-8.

28. Luyt C-E, Bréchot N, Demondion P, Jovanovic T, Hékimian G, Lebreton G, et al. Brain injury during venovenous extracorporeal membrane oxygenation. Intensive Care Med. 2016;42:897-907.

29. Cold GE, Christensen MS, Schmidt K. Effect of two levels of induced hypocapnia on cerebral autoregulation in the acute phase of head injury coma. Acta Anaesthesiol Scand. 1981;25:397-401.

30. Møller K, Skinhøj P, Knudsen GM, Larsen FS. Effect of short-term hyperventilation on cerebral blood flow autoregulation in patients with acute bacterial meningitis. Stroke. 2000;31:1116-22.

31. Aaslid R, Lindegaard KF, Sorteberg W, Nornes H. Cerebral autoregulation dynamics in humans. Stroke. 1989;20:45-52.

32. Newell DW, Weber JP, Watson R, Aaslid R, Winn HR. Effect of transient moderate hyperventilation on dynamic cerebral autoregulation after severe head injury. Neurosurgery Oxford Academic. 1996;39:35-44.

33. Zhang Y, Liu X, Steiner L, Smielewski P, Feen E, Pickard JD, et al. Correlation between cerebral autoregulation and carbon dioxide reactivity in patients with traumatic brain injury. In: Ang B-T, editor., et al., Intracranial press brain monit XV. Cham: Springer International Publishing; 2016. p. 205-9. https://doi.org/10.1007/978-3-319-22533-3 41.

34. Muizelaar JP, van der Poel HG, Li ZC, Kontos HA, Levasseur JE. Pial arteriolar vessel diameter and $\mathrm{CO} 2$ reactivity during prolonged hyperventilation in the rabbit. J Neurosurg. 1988;69:923-7.

35. Esteban A, Anzueto A, Frutos F, Alía I, Brochard L, Stewart TE, et al. Characteristics and outcomes in adult patients receiving mechanical ventilation: a 28-day international study. JAMA. 2002;287:345-55.

36. Esteban A, Ferguson ND, Meade MO, Frutos-Vivar F, Apezteguia C, Brochard $L$, et al. Evolution of mechanical ventilation in response to clinical research. Am J Respir Crit Care Med. 2008;177:170-7.

37. Esteban A, Frutos-Vivar F, Muriel A, Ferguson ND, Peñuelas O, Abraira V, et al. Evolution of mortality over time in patients receiving mechanical ventilation. Am J Respir Crit Care Med. 2013;188:220-30.

38. lida H, Ohata H, lida M, Watanabe $\mathrm{Y}$, Dohi S. Isoflurane and sevoflurane induce vasodilation of cerebral vessels via ATP-sensitive K+ channe activation. Anesthesiol J Am Soc Anesthesiol. 1998;89:954-60.

39. Nentwich J, John S. Current techniques for extracorporeal decarboxylation. Med Klin Intensivmed Notfallmedizin. 2019;114:733-40. 
40. Kazmi SO, Sivakumar S, Karakitsos D, Alharthy A, Lazaridis C. Cerebral pathophysiology in extracorporeal membrane oxygenation: pitfalls in daily clinical management. Crit Care Res Pract. 2018. https://doi. org/10.1155/2018/3237810.

41. Hunter C, Blood A, Bishai J, Hickerson A, Wall D, Peverini R, et al. Cerebral blood flow and oxygenation during venoarterial and venovenous extracorporeal membrane oxygenation in the newborn lamb. Pediatr Crit Care Med. 2004;5:475-81.

42. Ono M, Zheng Y, Joshi B, Sigl JC, Hogue CW. Validation of a stand-alone near-infrared spectroscopy system for monitoring cerebral autoregulation during cardiac surgery. Anesth Analg. 2013;116:198-204.

43. Rivera-Lara L, Geocadin R, Zorrilla-Vaca A, Healy R, Radzik BR, Palmisano $C$, et al. Validation of near-infrared spectroscopy for monitoring cerebral autoregulation in comatose patients. Neurocrit Care. 2017;27:362-9.
44. Steppan J, Hogue CW. Cerebral and tissue oximetry. Best Pract Res Clin Anaesthesiol. 2014;28:429-39.

45. Slupe AM, Kirsch JR. Effects of anesthesia on cerebral blood flow, metabolism, and neuroprotection. J Cereb Blood Flow Metab Off J Int Soc Cereb Blood Flow Metab. 2018;38:2192-208.

\section{Publisher's Note}

Springer Nature remains neutral with regard to jurisdictional claims in published maps and institutional affiliations.

\section{Submit your manuscript to a SpringerOpen ${ }^{\circ}$ journal and benefit from:}

- Convenient online submission

- Rigorous peer review

- Open access: articles freely available online

- High visibility within the field

- Retaining the copyright to your article

Submit your next manuscript at $\boldsymbol{\nabla}$ springeropen.com 